\title{
A ESTÉTICA DO SER-ÍMÃ DE HILMA AF KLINT: UM AMÁLGAMA ENTRE A CIÊNCIA E A FICÇÃO
}

SOUZA, Luciane Bernardi de ${ }^{1}$

RESUMO: Este trabalho realiza o movimento de bordear a relação entre a criação da artista sueca Hilma af Klint e as teorias científicas produzidas em sua época, relação esta que, num jogo de retroalimentação, explicita a força do imaginário na construção de realidades e deixa entrever como o conhecimento científico fertilizou seus trabalhos, posto que a ciência também está a todo o tempo sendo alimentada pela ficção. Para tal, adotamos aqui a perspectiva conceitual do filósofo alemão Hans Vaihinger (1911), que considera o impulso criativo e inventivo da ficção e da imaginação sobre a ciência, e desta última sobre a ficção.

PALAVRAS-CHAVE: Hilma af Klint, Hans Vaihinger, Ciência, Ficção.

\section{THE AESTHETICS OF THE HILMA AF KLINT: AN AMALGAM BETWEEN SCIENCE AND FICTION}

\begin{abstract}
This work makes the movement of embroidering the relationship between the creation of the Swedish artist Hilma af Klint and the scientific theories produced in her time, that in a game of feedback, explicit the power of the imaginary in the construction of realities and let us see how scientific knowledge fertilized his works, since science is also constantly being fed by fiction. To this end, we adopt here the conceptual perspective of the German philosopher Hans Vaihinger (1911), who considers the creative and inventive impulse of fiction and imagination over science, and the latter about fiction.
\end{abstract}

KEYWORDS: Hilma af Klint, Hans Vaihinger, Science, Fiction.

\footnotetext{
${ }^{1}$ Doutoranda em Literatura - UFSC. 


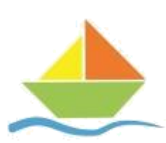

Em um mundo colonizado pelos indicadores de mercado e pela busca desenfreada por bens e serviços que nos arrastam para a esfera da racionalidade e da técnica, nosso distanciamento e nossa falta de diálogo com o mundo da ficção parecem alargar-se cada vez mais. Mas, na contramão desse movimento, é que o ato de abrir brechas no cotidiano para realizar o exercício intelectual da crítica e, consequentemente, da invenção criativa mostra-se transgressor, levando-nos a resgatar um desejo mais profundo (e humano) do que a procura pela permanência e pela certeza. Despontam, assim, as forças da inconstância, da criação e da imaginação, que, paradoxalmente, nos põem no prumo e tornam-nos conscientes de que a realidade e o ser são formas de ilusão que a todo o momento maquiam-se de verdade.

Porém, admitir a ficção ${ }^{2}$ como uma força indispensável em todos os âmbitos da vida humana implica uma inversão das formas tradicionais de relacionarmo-nos com a realidade, posto que a ficção, a partir da perspectiva conceitual adotada pelo filósofo alemão Hans Vaihinger (1911), amplia nossa visão sobre o real, sempre apreendido a partir de um determinado ângulo que se distancia da totalidade.

A consideração do impulso criativo e inventivo da ficção e da imaginação, por sua vez, leva-nos a revirar lacunas do cotidiano, a recriar passados esquecidos e presentes escondidos e a revisar os intervalos da história. Esse desejo flertante de rearmar passados e unir as pontas destes com o presente coloca-nos diante da obra - quase desconhecida - da artista sueca Hilma Af Klint, que se apresenta, segundo nossa perspectiva, como um ímã entre o espaço artístico e o discurso científico de sua época.

Nessa lógica, buscamos arquitetar uma moldura em que redes discursivas possam ser tecidas através de fios que, aparentemente opostos, se cruzam e geram imagens, pois, ao acreditarmos na força do encontro entre forças aparentemente "contrárias" que movem a vida, tentamos construir e descortinar aqui os mundos possíveis que a artista manifesta em sua obra, mundos estes que aproximam a ciência e a ficção e que, em seu âmago, são próximos, ainda que comumente sejam considerados contrários ${ }^{3}$.

Apontando para esse encontro, aproximamo-nos de seu trabalho esquadrinhando o que ele parece-me oferecer de mais potente: esse entrelugar, esse "ímã" criado pelo deságue entre campos distintos do conhecimento. Porém, não arquitetarei esta moldura sozinha. Convoco aqui

\footnotetext{
${ }^{2}$ Segundo a perspectiva de Hans Vaihinger (aqui adotada por nós), o conceito de ficção estende-se às noções que são frutos das necessidades intelectuais humanas e que acabam adquirindo valor de utilidade, pois, sem ela, as projeções intelectuais, os sentimentos e até mesmo as ações humanas não teriam o mesmo vigor. Para o filósofo, a ficção é um instrumento a partir do qual as ciências conseguem cumprir seus objetivos.

${ }^{3}$ A influência das descobertas científicas na criação da artista também é discutida no ensaio The metaphysical empiricism of Hilma af Klint (2015), pelo estudioso Tessel M. Bauduin.
} 
uma importante voz de transgressão quando o terreno abarca as relações entre a ciência e a ficção: a do filósofo alemão Hans Vaihinger, que, praticamente relegado na história da filosofia, dedicou grande parte de sua vida a escrever o tratado A filosofia do como se (2011) ${ }^{4}$.

Contemporâneo de Hilma af Klint, Vaihinger organizou inúmeros Congressos centrados na filosofia do Como se, nos quais cientistas das mais diversas áreas problematizaram o papel das ficções nas ciências e em outras áreas do conhecimento. $\mathrm{O}$ autor, que apresenta o germe do pensamento contemporâneo, pôs em xeque a estatística e a própria autonomia da ciência, afirmando que a única verdade existente é a ficcional. Em seu tratado, defende a consciência ficcionalizante do ser humano como elemento essencial para a edificação da ciência, como um artifício produtivo, desconstruindo a ideia da ficção como elemento desestabilizador de certezas e encontrada apenas na esfera estética. Vaihinger afirma que "o pensamento humano não opera sem ficções, sem mitos" (VAIHINGER, 2011, p. 68) e acredita que o conhecimento científico mascara-se de verdade, ainda que sempre deixe entrever, através de pequenas frestas, a presença vital das ficções. Sua percepção, assim, é a de que as ciências, em especial as exatas, trabalham com ficções, bem como a arte e a religião. Tal perspectiva é defendida por Vaihinger, em seu tratado, ao afirmar que:

O mundo de representações, conforme supúnhamos e achávamos, é subjetivo em suas formas; real é só o imutável e o observado, ou seja, subjetivos são os moldes que emprestamos ao que percebemos; o subjetivo é fictício; o fictício é incorreto; o incorreto é um erro. Os limites entre verdade e erro são, portanto, deslocáveis, à semelhança do que ocorre com todos esses limites [...] A verdade é tão somente o grau mais conforme aos fins do erro e este o grau menos conforme aos fins da representação, da ficção. Chamamos o nosso mundo de representações do verdadeiro quando nos faculta melhor a objetividade e de agir nele. (VAIHINGER, 2011, p. 264)

Apesar da inversão do referente em relação à filosofia proposta por Vaihinger - visto que este estava interessado na ficção como base da ciência e não na ciência como base da fícção -, na criação de Hilma af Klint visualizamos o movimento de aproximação entre esses dois universos, o científico e o ficcional/da representação. Essa aproximação, segundo a minha

\footnotetext{
${ }^{4}$ Obra escrita em sua juventude, A filosofia do como se foi publicada somente em 1911, sendo o motivo para esta publicação tardia a certeira intuição do filósofo de que sua obra causaria um verdadeiro curto circuito no mundo científico, ao defender como base do conhecimento científico a ficção.
} 


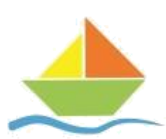

perspectiva, produz fissuras que geram o espaço do encontro, espaço este que ainda parece ser ignorado pelos estudos contemporâneos sobre a artista, muito mais interessados em projetá-la segundo um viés "transcendental" e "místico". Tal leitura, que nos parece um pouco restrita por enfatizar somente as potencialidades religiosas e esotéricas de sua obra, ignora a estética deslizante e dialógica que a criação da artista apresenta entre esses dois mundos pulsantes da ciência e da arte e que, segundo Vaihinger, são igualmente e potencialmente ficcionais.

Independente das leituras e perspectivas críticas adotadas em relação ao trabalho de Af Klint, é inquestionável que, atualmente, ocorre certa agitação em torno do mesmo, com fluxos críticos que se justificam por recentemente ter sido atribuído a ela o título de precursora da arte abstrata, remexendo, assim, os lugares até então fixos da história da arte ocidental e dinamitando aqueles reservados à vanguarda abstracionista masculina, em especial a Wassily Kandinsky (1839-1944), Piet Mondrian (1832-1944) e Kazimir Malevich (1879-1935). Contudo, o acanhamento crítico ${ }^{5}$ em relação à sua obra ainda é significativo e é esta falta que motiva um olhar atento para a obra da artista, olhar que tenta ir além das considerações, às vezes bastante unidirecionais e romantizadas, de Af Klint como uma "sacerdotisa mediúnica" e "pioneira da abstração".

Assim, este exercício crítico-imaginativo realiza o movimento de bordear a relação entre a criação de Hilma af Klint e as teorias científicas produzidas em sua época, que, num jogo de retroalimentação, explicita a força do imaginário na construção de realidades e deixa entrever como o conhecimento científico fertilizou seus trabalhos, posto que a ciência também está a todo o tempo sendo alimentada pela ficção, segundo a perspectiva defendida por Vaihinger.

\section{HILMA AF KLINT: UM VÓRTICE MULTITEMPORAL À MARGEM DE SEU TEMPO}

O passado fala do presente e nós, enfim, chegamos ao futuro que Hilma af Klint tanto desejava quando, em seus cadernos, registrou que as inúmeras caixas que guardavam sua obra fossem abertas somente 20 anos após a sua morte ${ }^{6}$. Entretanto, não é ao presente, mas a um verdadeiro vórtice multitemporal que sua obra arremessa-nos: turbilhão e fusão de tempos passados,

\footnotetext{
${ }^{5}$ Uma das possíveis explicações para tal é a de que suas pinturas só podem ser visualizadas por meio de reproduções, já que nenhuma delas está atualmente exposta nem incluída em coleções de museus.

${ }^{6}$ Tal atitude, que visava a não exposição de sua obra, aproxima-se muito a do teórico Hans Vaihinger, que, como mencionado anteriormente, publicou A filosofia do como se muito tempo após a sua escrita.
} 


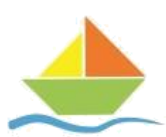

futuros e presentes que assentam a necessidade e certeza de que a História deve ser constantemente revisitada, refeita e reescrita, de modo que possamos resgatar fatos e indivíduos que, por inúmeros motivos, foram marginalizados e colocados em um lugar secundário. E Hilma af Klint, assim como Hans Vaihinger, são exemplos de como esses movimentos de desdobramento e revisão histórica não são apenas necessários, mas fundamentais na construção do conhecimento, seja ele estético ou filosófico.

No ano de 1886, Estocolmo, lugar de geografia longínqua e sem tradição de revelar grandes nomes da arte, tornou-se o berço daquela que seria considerada a pioneira da arte abstrata: Hilma af Klint. Nessa terra escandinava, a talentosa e atemporal artista concebeu sua obra, que abrange mais de 124 cadernos com mais de 26.000 páginas de manuscritos com estudos, tratados espirituais e filosóficos e 1.400 pinturas ora de caráter figurativo, ora abstrato de cunho esotérico e místico ${ }^{7}$. A artista, que desejava que sua produção fosse compreendida por seu público, acreditava que as gerações futuras estariam mais preparadas para compreendê-la, uma vez que tinha a consciência do que ela representava.

De 1882 a 1887, a artista, aos 20 anos, ingressou na Academia Real de Artes da Suécia, em Estocolmo, onde desenvolveu inúmeras técnicas de retrato e paisagem na pintura ${ }^{8}$, sendo que, durante sua vida, expôs apenas retratos e paisagens de cunho realista-naturalista.

No entanto, os movimentos espirituais em voga na época (Espiritismo, Teosofia, Antroposofia, entre outros) tiveram grande influência sobre sua obra, que deixa entrever as diversas reflexões que essas doutrinas apresentavam. Desse modo, a maior parte de seus trabalhos é formada por séries que exploram a espiritualidade e que enfatizam as nuances da existência humana, séries nas quais o micro e o macrocosmo são refletidos através de dualidades, estudos de cores (havia, em suas anotações, um estudo das cores e suas correspondências com os sentimentos, de acordo com um dicionário criado por ela), formas orgânicas e geométricas, além de forte simbolismo.

Pertencente a este universo que relacionava arte, ciência e espiritualidade, no ano de 1896, Klint e mais cinco amigas artistas fundaram o grupo De Fem, mais conhecido como "As Cinco", o qual se reunia todas as sextas-feiras para reuniões de cunho espiritual. A artista, a partir desse grupo, apresenta uma mudança radical em seu trabalho, pois é quando começa a pintar obras não miméticas (por volta de 1905). Intitulando-se médium, afirmava estar em contato com seres espirituais que lhe enviavam mensagens consideradas importantes por ela.

\footnotetext{
${ }^{7}$ ROLIM. José Henrique Fabre. Hilma af Klint, complexidade filosófica da existência. 2018

${ }^{8}$ Estas informações biográficas são apresentadas no recente trabalho Hilma af Klint: do espírito à matéria (2019), de Anna Carolina Cheles Cruz.
} 


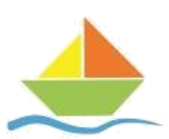

Essa experiência impactou o seu trabalho artístico durante a maior parte de sua vida, dado que creditava ter sido contatada por esses mestres superiores para um grande projeto em que pintou centenas de telas que resultaram na série Pinturas para o templo (1906-1915).

Porém, ainda que tenha mantido intensos estudos de cunho religioso, esses não a fizeram afastar-se de estudos científicos de sua época e foi exatamente esse fluxo heterogêneo de referências que proporcionou uma aproximação da artista com a Teosofia, de Helena Blavatsky (1831-1891) e Rudolf Steiner, a qual seria, futuramente, uma das ricas nascentes inspiradoras de seu trabalho. Muitos artistas abstratos da época voltaram-se para a Teosofia, doutrina religiosa e filosófica surgida no século XVII, na qual grande parte dos artistas denominados de abstracionistas buscava certa explicação para a realidade. A arte de cunho abstrato por eles produzida possuía um potencial espiritual muito grande: em especial, teria a capacidade de auxiliar na sublimação do espectador, pois transfiguraria e aprofundaria a posição desse diante de questões de ordem espiritual.

No entanto, a Teosofia, que se caracterizava por sua multidisciplinaridade, procurava apoiar-se nas ciências ao mesmo tempo em que criticava uma cegueira da ciência institucionalizada. Para Klint, a realidade não estava apenas configurada em termos do visível, apenas no mundo físico, mas também a partir de mundos paralelos ao mundo material e, em sua obra, constatamos esta fusão, de modo que ocorre uma leitura espiritualizada da ciência, resultando, por fim, numa arte atemporal que busca o invisível aos olhos humanos.

Sua aproximação e curiosidade em relação às descobertas científicas da época, que buscavam tornar o invisível visível e descobriam cada vez mais invisibilidades visíveis, fez com que a artista criasse a partir da perspectiva de que as dimensões internas são tão verdadeiras e reais quanto as do mundo visível, tocável e palpável. Essa visão presentifica-se em sua obra através de quadros com figuras orgânicas e símbolos alquímicos, formas geométricas e palavras, uma vasta criptografia de mensagens oferecidas ao mundo material que a própria artista buscava decifrar.

Em A filosofia do como se, ao equalizar termos e significados diversos em seu conceito de "ficção", Vaihinger dialoga com Nietzsche e destaca que, na medida em que inevitável do ponto de vista teórico e necessária do ponto de vista prático, toda e qualquer ficção é válida e justificável, mesmo aquelas que Nietzsche tanto criticou, como as relacionadas à religião: "Nietzsche, após ter revelado tão implacavelmente o lado nocivo das representações religiosas, teria necessariamente ressaltado também os seus aspectos positivos, reconhecendo-as como ficções úteis, até mesmo como necessárias" (VAIHINGER, 2011, p. 667). E isso parece ser o 
que vemos em Af Klint, que buscou nesse mundo espiritual (tão ficcional como no mundo imaginário da ciência) o material para sua criação.

Catapultando Af Klint para o contemporâneo, destacamos que foi no ano de 1986 que ocorreu, em Los Angeles, no County Museum of Art, a sua primeira exposição póstuma, na mostra intitulada The Spiritual in Art: Abstract Paintings 1890-1985. Tal projeção deu visibilidade global à artista, divulgando sua obra para países como a Alemanha, Espanha, Dinamarca e Noruega e permitindo que, aos poucos, sua criação fosse reconhecida internacionalmente. No Brasil, sua presença foi mais recente, em 2018, na Pinacoteca de São Paulo, onde ocorreu a mostra Hilma af Klint: Mundos Possiveis, com cerca de 130 obras de seu acervo, inclusive algumas que nunca haviam sido apresentadas ao público. Uma exposição itinerante também levou seu trabalho a importantes museus como os de Estocolmo, Berlim, Málaga, Londres, e inúmeros outros países.

Assim, após quase sete décadas de esquecimento, a artista vem conquistando certo reconhecimento, sendo considerada, hoje, uma das mais importantes artistas modernas. Seu trabalho, que está para além de apresentar apenas uma única perspectiva do mundo, pode ser interpretado como uma tentativa de profundo entendimento da(s) realidade(s) e da existência humana, pois, em sua obra, encontramos essa fusão de interesses e um imbricamento entre mundos distintos justamente em um momento (final do século XIX e início do século XX) em que tudo estava radicalmente polarizado (bem e mal, direita e esquerda, religiosidade e progresso).

Desse modo, a artista, que cria a partir de elementos díspares, confronta a cisão desarmônica entre as diferentes áreas do conhecimento, que, em sua arte, entrelaçam-se, pondo em tensão o secular e o divino, o tradicional e o moderno, o espiritual e o científico de maneira única e bastante diversa do que viria a ser feito pelos abstracionistas.

\section{A ARTE DE HILMA AF KLINT: UM DIÁLOGO ENTRE A CIÊNCIA E A FICÇÃO}

Como não poderia ser diferente, se a ficção atua sobre a ciência, esta atua a todo o momento sobre a ficção em um movimento contínuo de trocas e realimentação ${ }^{9}$. É nesse contato próximo entre essas áreas do conhecimento que constatamos que o entendimento e a busca por uma compreensão mais racionalizada da realidade apresentam limites, sendo na borda desta

\footnotetext{
${ }^{9}$ Vale lembrar aqui que a Literatura desde sempre apresentou diálogos próximos com a ciência através de nomes como Jorge Luís Borges, Isaac Asimov, Júlio Verne, Úrsula Le Guin, George Orwell, entre muitos outros escritores que realizaram essa ponte e contato.
} 


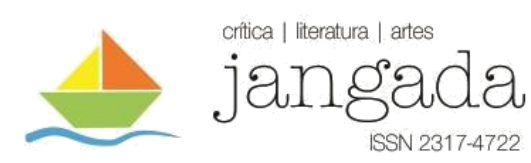

limitação que a força imaginativa encontra seu pulso. Mas isso não é novidade, afinal, a ciência (qualitativa), fundada em argumentos lógicos e na imaginação, historicamente, alicerçou-se sobre a ideia de que o que não se compreende imagina-se e cria, estando, assim, a ficção como base de todo o pensamento científico.

Foi no âmago de um mundo científico em efervescência, no qual irrompiam inúmeras descobertas, que Hilma af Klint produziu; momento no qual a ciência redescobria-se e transformava-se tão velozmente quanto a própria sociedade: a Teoria da Evolução de Charles Darwin (1859), a descoberta de ondas eletromagnéticas (1886), a difração de raios-X por Max von Laue (1895), as partículas subatômicas (1897), o decaimento radioativo (1898), a teoria da relatividade restrita de Albert Einstein (1905), a definição do número atômico de Henry Moseley (1913) e, na matemática, a possibilidade teórica de uma quarta dimensão romperam os limites entre realidades visíveis e não-visíveis e elevaram as visões do homem diante do(s) mundo(s). E a emoção sobre o invisível tornando-se visível tomou conta da cultura finissecular.

Em 1897, o físico escocês Charles Thomas Wilson, na Universidade de Cambridge, inventou a "câmara de nuvens": um detector capaz de mostrar partículas alfa emitidas por uma fonte radioativa. Sua invenção, que foi, primeiramente, fruto de muita imaginação, ocorreu como resultado de uma expansão repentina do volume de ar em um vaso fechado saturado com vapor de água, de modo que tal expansão gerou uma queda na temperatura e tornou o ar supersaturado, resultando, consequentemente, na condensação das partículas. A partir desse invento, Wilson explorou como os íons serviam como núcleos para gotículas de água, fotografando a formação dessas gotículas e sua trajetória, ou seja, materializando-as. Posteriormente, no ano de 1910, ele descobriu que poderia usar seu dispositivo de câmara de nuvem para detectar partículas carregadas, uma vez que elas deixariam um rastro de íons - e gotas de água - enquanto passavam pelo gás na câmara, que ficou popularmente conhecida como Câmara de Wilson. O resultado foi a imagem que segue abaixo (Fig.1): 


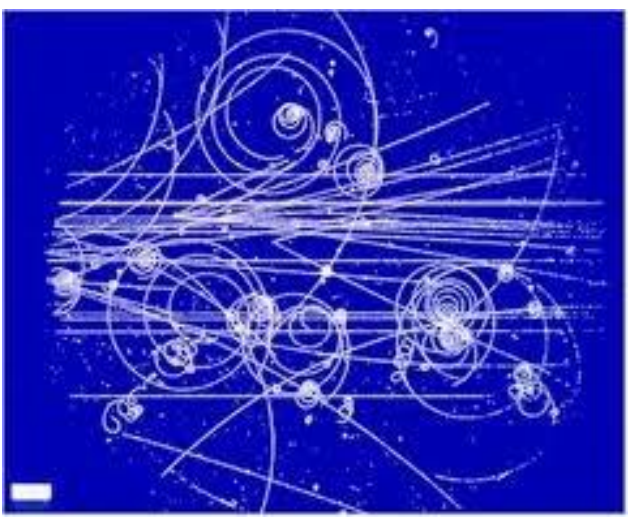

Fig. 1: Faixas curvas de partículas carregadas em uma câmara de nuvem de campo magnético.

O registro dessa matéria em movimento, antes somente possível no nível da imaginação e da ficção, tornou-se possível e visível. Caótico em sua essência, e não submetido ao controle e organização, esse movimento das partículas curiosamente aproxima-se - no âmbito da especulação, obviamente - da aparente dinâmica de fluxos presente no trabalho Primordial Chaos de Hilma af Klint, no qual a matéria universal, antes somente virtual, agora parece estar sendo concretizada esteticamente pela força da imaginação, de modo a formar um universo único, não existente e, até então, sem referências na realidade material.

Um ano depois que Wilson descobriu a câmara de neblina, o também físico e engenheiro alemão Wilhelm Roentgen produziu e detectou radiação eletromagnética nos comprimentos de onda correspondentes aos atualmente chamados raios-X. Em uma impressão de uma das primeiras fotografias, encontramos a mão esquerda de sua esposa, Anna Bertha Ludwig, que, diante da exposição dos ossos de sua mão, supostamente afirmou, com surpresa, estar diante da própria morte.

Essas revelações sobre mundos que não podiam ser vistos a "olho nu" e que, de repente, a partir de inventos, se apresentaram ao homem de forma concreta exerceram fascínio sobre as correntes ocultistas como o Espiritismo, a Teosofia e a Antroposofia. Ainda nessa época, existiam relações (tênues) que ligavam a ciência e o pensamento espiritual de várias maneiras, posto que pesquisadores realizavam experimentos para testar crenças espíritas e pensadores espirituais, por sua vez, incorporaram a ciência em suas práticas, em grande parte para legitimar suas ideias.

Um exemplo disso é Helena Blavatsky, fundadora da Sociedade Teosófica, que estava atenta aos experimentos e às descobertas de cientistas (como J. J. Thomson, Frederick Soddy, Rutherford e Marie e Pierre Curie) que validavam a prática de seus ensinamentos sobre 


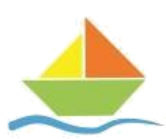

Alquimia e reinos espirituais. Assim, noções relacionadas à ciência não foram transmitidas apenas por cientistas, mas também por pensadores espirituais e religiosos que filtraram inúmeros conceitos científicos por meio de suas próprias crenças subjetivas. Nessa mesma época, proeminentes cientistas como o astrônomo Camille Flammarion, o químico William Crookes e o físico Oliver Lodge estavam profundamente interessados em aspectos do ocultismo, atestando que o mundo esotérico não estava afastado dos centros de conhecimento científico ${ }^{10}$.

Hilma af Klint, vivenciando esses desenvolvimentos, incorporou muitas dessas noções e descobertas ao seu trabalho, inclusive dedicando séries inteiras aos conceitos de átomo e evolução, duas ideias centrais em discussão na época. No entanto, considerando o seu mergulho profundo nas crenças e teorias espirituais (em especial a Teosofia) às quais se filiou, é possível afirmar que, provavelmente, muitos conceitos científicos foram mesclados à perspectiva desses movimentos com os quais ela estava em sintonia. A sua compreensão do conceito de evolução, por exemplo, apresentada em sua série Evolution (1908), não veio puramente de A Origem das Espécies, de Darwin (1859), mas de uma noção de evolução natural que perpassa a espiritual, como afirma a teórica Catharine Zegher ${ }^{11}$, estudiosa da obra de Af Klint.

Sobre essas diferentes formas de engendrar o conhecimento, Deleuze e Gattari (1980), em $O$ que é filosofia, afirmam que a ciência e a arte são formas de pensar distintas que utilizam recursos e fazem leituras diferentes do mundo, mas que, no entanto, compartilham o desejo de tentar conceituar, sistematizar ou representar o caos, mergulhando nele com ou sem ilusão de segurança. Interessante na afirmação dos teóricos é a presença da "ilusão", que, segundo eles, perpassa tanto a ciência quanto a arte. A diferença maior é que enquanto a primeira afastaria essa ilusão de segurança, a segunda a abraçaria. Afinal, é justamente com a força da ficção que o ser humano encarou, desde os primórdios, os mistérios da natureza, valendo-se sempre de metáforas e elementos simbólicos que rompem as fronteiras entre ciência, religião e criação estética. Nessa perspectiva, Af Klint parece ter contemplado tanto as ficções e magnitudes da ciência moderna - as dimensões do espaço, a evolução das espécies, e a estrutura física do átomo - quanto as do campo estético e espiritual.

Quando em 1897 ocorreu a descoberta de que átomos continham elétrons carregados negativamente (e, portanto, não eram a menor unidade da matéria) e, em 1911, a descoberta do

\footnotetext{
${ }^{10}$ Ainda que fosse interessante realizar um regresso aos movimentos que resultaram na separação entre a ciência e a religião, não nos ateremos a esse ponto, visto que o tópico pede um espaço e momento mais propício.

11 Ainda que este não seja o foco de seu estudo, a autora desenvolve uma breve discussão desse aspecto em seu trabalho "Abstract," in $3 \times$ Abstraction: New Methods of Drawing; Hilma af Klint, Emma Kunz, and Agnes Martin (2005).
} 


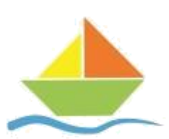

núcleo positivo do átomo, a artista, em conexão com tais descobertas, em 1917, apresentou a série Atom, na qual desenvolve de forma esquemática e abstrata sua percepção acerca desse elemento. Entretanto, a noção de átomo na série não parece vinda diretamente do Modelo de Rutherford, visto que a Teosofia de Rudolf Steiner defendia, por exemplo, que o átomo poderia ser observado através de processos de clarividência.

Nos trabalhos de Af Klint, as aquarelas que apresentam átomos estão dimensionadas por um significado pessoal, uma roupagem espiritual, de modo que sua exploração altamente imaginativa das estruturas atômicas parece ser o resultado de suas próprias investigações espirituais e visões subjetivas, que se somam à sua curiosidade e ao interesse pelo mundo natural. Suas inclinações ocultistas, combinadas aos interesses científicos, influenciaram sua metodologia e estilo, que variou da abstração geométrica a uma forma primitiva de surrealismo. Para ela, a ciência não é a voz monolítica que deseja ser a expressão da verdade definitiva e irrefutável, nem a base que garante a busca da verdade, do descobrimento e da verificação através de construções arbitrárias, mas sim mais uma possibilidade conceitual e imaginativa para interagir e criar.

A partir desse entendimento é que o trabalho de Af Klint, em The Atom Series, consegue desarmar verdades absolutas e afirmar possibilidades variadas diante do que já existe e do que pode existir. Sua arte torna-se um lugar de centrifugação, um amálgama de universos distintos, um espaço de risco, do encontro, um espaço que potencializa mundos novos.

É nessa fronteira do improvável, que produz e inverte expectativas renegando ordens aparentemente fechadas e posições estáveis, que a artista explora as fronteiras porosas desses diferentes sistemas de conhecimento. Af Klint elabora o novo através de encontros que desmitificam limites e descortinam possibilidades ao negar as relações binárias originadas da lógica e de conteúdos rigidamente estabelecidos, relações estas que tentam organizar o arquivo do mundo, sempre anárquico, provisório e em contínua transformação.

O discurso vaihingeriano, de que vida não é possível sem representações imaginadas, sem representações falsificadas, parece ecoar em seu trabalho. Ainda que a diferença entre a ficção estética e a científica seja fundamentalmente o fato de que a primeira parte de uma criação consciente da aparência estética, enquanto, na segunda, a ficção desempenha um elemento necessário para se chegar à verdade, tornando-se, ainda que ficção, verdadeira a partir da experiência e da eficácia, o elemento ficcional é, em ambos os campos, um elemento útil nesse processo de busca e transformação da realidade. O discurso da ciência, através da ficção, 
criaria, segundo Vaihinger, um mundo possível, uma hipótese que, depois, se comprovaria. Sobre a potência imaginativa, em seu tratado, o filósofo afirma:

\begin{abstract}
Nosso intelecto opera com símbolos conscientes, imagens e figuras retóricas, com "abstrações grosseiras e insuficientes", com metáforas: tempo, espaço e causalidade não são senão metáforas favoritas. Assim "vivemos e pensamos completamente sob os efeitos constantes do não lógico, no âmbito da ausência de saber e do saber do falso [...] "A formação de metáforas é o instinto básico do homem. Este impulso artístico, designado simplesmente "instinto mítico", assim o conduz a criar construções falsas também no campo da teoria do conhecimento. Em princípio, estas são geradas de forma inconsciente, entretanto, "para o intelecto liberado", são meios auxiliares consciente: “armaduras". (VAIHINGER, 2011, p. 638)
\end{abstract}

Assim, a linguagem estética da artista, aberta e simbólica tanto quanto a ciência, é resultado do estrondo gerado pelo encontro entre essas duas áreas do conhecimento - uma vez que, segundo Vaihinger, nosso pensamento atua a todo o momento através da criação e da invenção, que atinge a todos os espaços do conhecimento. Nos trabalhos de Af Klint, desenlaçase o desmedido, a invenção, a possibilidade de realidades imagéticas afetadas pelo conhecimento científico, que também avança com a força da imaginação e do acaso. É nesse movimento de atravessamento, para além da metafísica e da ciência, que ela opera e cria e que, aliada à imaginação, concretiza tal enleio e enlaço numa dança furtiva de trocas e contatos.

\title{
UM OLHAR SOBRE O MATERIAL-IMATERIAL EM THE ATOM SERIES (1917)
}

Expressão que em grego significa "indivisível”, a palavra átomo vincula-se rigorosamente ao conceito de matéria, a tudo o que tem massa e ocupa lugar no espaço. Essa concretude e não divisibilidade material foi, a princípio, o que inspirou inúmeros modelos atômicos que afirmavam que o átomo era maciço e indestrutível. Da "bola de bilhar" de Dalton (1803) ao "pudim de passas" (1904) de Thomson, havia certa segurança na concretude desse elemento.

No entanto, foi no ano de 1911, na Universidade de Manchester, que o físico-químico Ernest Rutherford, juntamente com Hans Geiger e Ernest Marsden, descobriu a natureza nuclear do átomo, que ganhou o nome de "Modelo de Rutherford", ao "dividir" o átomo, em seu laboratório, desintegrando o núcleo de nitrogênio. O cientista britânico mostrou como o modelo 
atômico de J. J. Thomson estava "equivocado". Sua descoberta revelou que a carga positiva de um átomo está concentrada no seu centro (hoje conhecido como o núcleo) e que este é orbitado por baixa massa de elétrons.

Anos depois da descoberta de Rutherford, no ano 1913, em Copenhague, Niels Bohr refinou ainda mais o modelo atômico do colega, descrevendo que o curso de elétrons em torno do núcleo realiza-se em órbitas circulares, movimento muito semelhante ao do sistema solar, mas que, ao invés da gravidade, os elétrons são atraídos por forças eletrostáticas. Amplamente relatadas em todo o mundo científico ocidental, tais descobertas tiveram imensas implicações não somente para o mundo científico, uma vez que o átomo, sempre imaginado como um objeto tangível, não mais "existia”, pois havia se transformado em uma "bola de vácuo" com um minúsculo núcleo. Assim, o modelo atômico de Rutherford- Bohr escamoteou as certezas até então inalteráveis e deixou-nos imersos em uma atmosfera incerta e angustiante. A própria matéria, de repente, não era mais material, enigmatizando o vazio absoluto.

Entretanto, antes dessas descobertas tornarem-se "verdades absolutas", foram, nos termos de Vaihinger, primeiramente, "representações falsas", porém úteis, pois conferiram ao lugar da ficção na ciência a mesma dignidade de outras operações mentais, uma vez que não foram obstáculos à razão, mas, ao contrário, aparências a serem dissuadidas na busca pela essência verdadeira, como se preconizou durante grande parte da história da metafísica.

Assim, em contato com uma realidade que também passa pelo crivo da ilusão e da imaginação, alguns trabalhos de Af Klint dialogam não somente com o pensamento do filósofo alemão, mas também com o do checo Vilém Flusser (2011), para o qual a origem de todas as certezas aceitas como naturais são, primeiramente, "ilusórias". O "fazer como se", de Vaihinger, ecoa no pensamento desse pensador e ajuda-nos a entender experiências de natureza paradoxal, não somente aquelas relativas ao campo científico, mas também aquelas derivadas da esfera religiosa. Segundo o teórico, quando falamos em alma ou em substância, estamos, a princípio, lançando mão de ficções úteis que nos auxiliam no tratamento unificado de certas concepções mentais e que, assim como a ciência, provida de caráter humano, apresentam, na ficção e na especulação mental, ferramentas para explorar de modo mais eficiente a realidade.

Nessa perspectiva, o crítico da obra de Af Klint, Raphael Rosenberg, ${ }^{12}$ afirma que as obras da artista são pura imaginação, abstração de cor e forma, uma vez que geram contextos invisíveis, tornando-os visíveis através de imagens que apresentam algo que, como tal, não é materialmente concebível nem palpável. Nesse sentido, mesmo que não sejam miméticas no

${ }^{12}$ Was There a First Abstract Painter? Af Klint's Amimetic Images and Kandinsky's Abstract Art (2015). Jangada | nr. 14, jul/dez, 2019 | ISSN 2317-4722 32 | P á g in a 
sentido convencional, ao não imitarem o que pode ser visto concretamente, apresentam algo: o inefável ou super-sensível. Seus círculos geométricos e concêntricos, bem como as cores que utiliza, fazem de sua obra um lugar de transbordamento de significados, gerando mundos possíveis nos quais algo que não existia passa então a existir.

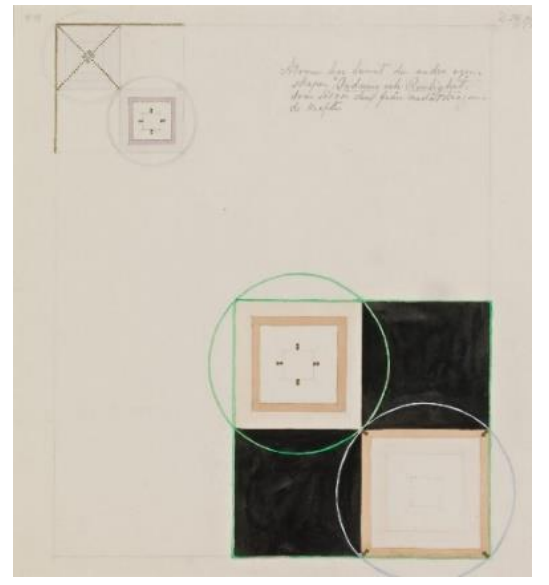

Fig 3. Hilma af Klint, The Atom Series. no. 15,1917 . Aquarela sobre papel $(27 \times 25 \mathrm{~cm})$

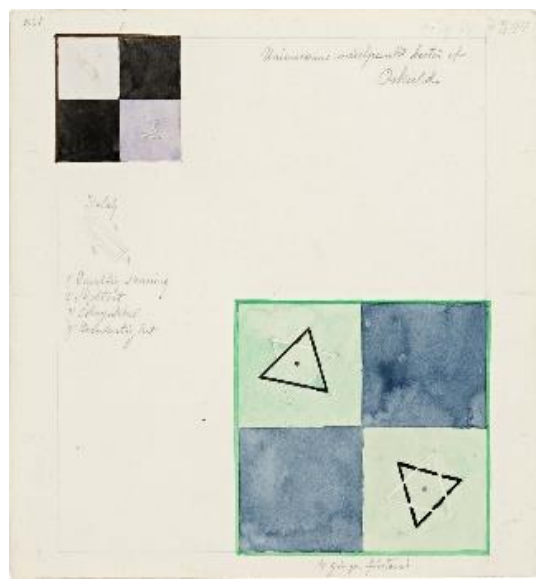

Fig 4. Hilma af Klint, The Atom Series no. 17, 1917, Aquarela sobre papel $(27 \times 25 \mathrm{~cm})$

Pareceu-nos importante selecionar duas aquarelas da série Atom (no total são vinte e duas): $\mathrm{a}^{\mathrm{o}} 15$ e $\mathrm{a} \mathrm{n}^{\mathrm{o}} 17$, que correspondem às imagens acima. Diante delas, poderíamos afirmar que "não há nada a explicar, nada a interpretar", uma vez que nos trabalhos de Af Klint encontramos aquilo que Deleuze e Guattari denominam "pura máquina abstrata” (DELEUZE; GUATTARI, 1980, p. 34).

Todavia, partindo de um quadro conceitual um pouco diverso, mas não menos importante, a teoria do efeito estético afirma que somente por meio da assimetria que se dá no ato de leitura, só a partir dos chamados vazios estabelecidos na interação entre obra e leitor (espectador), poderá ocorrer certa comunicação. É nesse momento que entra em jogo a ação do imaginário enquanto projeção daquilo que ainda não existe. Como apresenta-nos o teórico Wolfgang Iser, em $O$ ato da leitura:

A comunicação seria desnecessária se ela não transmitisse algo que não fosse desconhecido. Por isso, a ficção se determina como comunicação, pois graças a ela vem algo à luz do mundo que não está aí. Isso precisa revelar-se a si mesmo para ser apreendido. Mas como os diversos graus da não-familiaridade não se manifestam sob as condições que valem para o que é familiar, aquilo 
que deve sua emergência à ficção só pode manifestar-se como negatividade (ISER, 1999, p. 195).

Portanto, a comunicação será sempre um processo inventivo de pura ficção e jogo: o espectador constrói os sentidos por meio do que não há, permitindo que, assim, se desenvolvam inúmeras possibilidades de interpretação nos mais diferentes contextos. Nesse sentido, diante das aquarelas em questão, não se esgotaria o sentido naquilo que é visto, pois, objetos estéticos, levam-nos a pensar "para além do princípio de visibilidade e da oposição canônica do visível e do invisível”, como afirma Didi-Huberman (1998).

As duas imagens, que dimensionam formas aparentemente estáticas, aproximam-se em vários aspectos uma da outra por apresentarem, no canto superior esquerdo, um quadrado maior dividido em quatro quadrados menores, com interseção e linhas diagonais em cruzamento. Já no canto inferior direito, visualizamos um quadrado maior dividido de maneira semelhante ao superior, por apresentar quadrados menores. O primeiro quadrado- menor e superior -, como em um jogo de reflexos, parece estar espelhando a imagem maior - da parte inferior da aquarela.

Em ambas as obras, que se aproximam da apresentação do átomo, este é apresentado de modo diagramático em dois planos gráficos que geram a impressão de que a artista busca mostrar a "frente" e o "verso" desse elemento. Tal apresentação em dois planos pode ser considerada como duas possibilidades de leitura desse elemento, entendendo-o a partir daquilo que se mostra e daquilo que (quase) não se mostra. Assim, as duas aquarelas, que apresentam proximidades quanto ao aspecto formal, podem estar apontando para o comportamento do átomo em dois planos e perspectivas distintas.

Nessa perspectiva, considerando a relação da artista com a crença em outras esferas da realidade, uma possível leitura que se apresenta é a de que esses dois planos do átomo poderiam estar correspondendo ao plano terreno (parte inferior da imagem) e ao plano etéreo (plano superior da imagem), que, existindo simultaneamente em espaços virtuais, estariam explicitando a possibilidade de coexistência de diferentes pontos de vista do mesmo fenômeno.

A noção deleuziana de diagrama parece dialogar com os trabalhos de Af Klint ${ }^{13}$ nesse aspecto, não em função da presença de traços geométricos que nos remetem à imagem comum e matemática de diagrama, mas sim pelo fato de apresentarem possibilidade de descrever tanto

\footnotetext{
${ }^{13}$ Essa aproximação também já foi realizada em outros estudos. Aqui referenciamos o recente trabalho de Jadranka Ryle, intitulado: Feminine Androgyny and Diagrammatic Abstraction: Science, Myth and Gender in Hilma af Klint's Paintings (2019).
} 


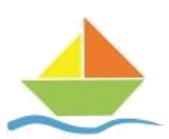

como as coisas são como de sugerir como poderiam ser, visto que o diagrama não se limita a uma realidade social ou ontológica, mas reconfigura dados para traçar futuros potenciais, que podem assumir dimensões virtuais, tendo, assim, por base, a ficção.

É em Mil Platôs que Deleuze e Guattari desenvolvem essa noção de diagrama. Segundo a perspectiva dos autores, o diagrama serve como veículo que alcança o que há por vir e que, assim, estende as possibilidades de pensamento para além de realidades já estabelecidas: "O diagrama não funciona para representar mesmo algo real, mas constrói um real que ainda está por vir, um novo tipo de realidade" (DELEUZE; GUATTARI, 1980, p. 100). Nesse sentido, o conceito serve para pensar um regime de signos que instaura um novo modo de conceber a repartição entre conteúdo e expressão, entre significado e significante, para além, estabelecendo conexões, não com o objetivo de representar algo real, mas constituir um real por vir.

Pensar as obras de Af Klint sob a perspectiva diagramática e como uma forma de manifestação que encontra em si seu próprio fim, leva-nos à leitura das aquarelas como potências com certa vocação para o inapreensível, posto que apresentam um espaço de transgressão da ordem - espaço ilimitado que tem por matéria o "não visível”. As duas aquarelas são modos de conhecimento que induzem a experiências que forçam a fronteira do real ao encenarem o impensável. Acionando nossos sentidos, elas arrebatam ao proporcionarem uma experiência limite, uma "saída de si”, que está além da nossa compreensão lógica-racional, apresentando uma arquitetura de ideias que geram blocos de sensações e intensidades que eternizam o virtual e configuram espaços nos quais os limites lógicos e racionais são transgredidos e reconfigurados, sendo, nos termos de Bataille (2013), a manifestação exata da "pura perda".

O teórico Alexandre Kojéve, que, no ano de 1936, escreveu um texto intitulado Las pinturas concretas de Kandinsky, discutiu neste os conceitos de representação e nãorepresentação em pintura. $\mathrm{O}$ autor, contrariando o sentido comum atribuído à expressão "abstrata", inverte a compreensão comum desse termo ao considerar a arte abstrata como concreta e a arte considerada comumente "concreta", abstrata, invertendo, assim, o conceito de "pintura abstrata". Segundo ele, é, na verdade, a pintura representativa que abstrai da realidade a beleza de algo que já existe (um objeto) e, ao abstrair essa beleza e concretizá-la em uma pintura, faz com que seja considerada abstrata e subjetiva.

Já a pintura de Kandinsky aparece para Kojéve como completa, inexistente no mundo real não artístico, sendo, assim, mais concreta e não representativa, pois o belo não é extraído 
de um objeto real ou fora dele. O que há no quadro não foi extraído de uma realidade exterior, não existe fora do quadro: é uma beleza criada pelo artista, que não existe em outro lugar. Segundo o autor,“Al no ser extraído ni abstraído, sino creado de una vez, se trata de algo concreto"14 (KOJÉVE, 2007, p. 41 e 42).

Nessa perspectiva, as aquarelas de Af Klint, com suas linhas e círculos, formam um universo em si mesmo, que não existe fora do quadro. Assim, suas pinturas são concretas e objetivas, criam um universo em si, universo completo que dialoga com o mundo (em especial o mundo da ciência) e que, ao mesmo tempo, mantém-se autônomo deste. Kojéve realiza a seguinte afirmação sobre a obra de Kandinsky (mas que aqui pode também ser considerada para a obra de Klint): "son Universos completos y reales que existen en-por-y para sí mismos en la misma medida que es el Universo real no artístico"15 (KOJÉVE, 2007, p. 51 e 52).

Nesse sentido, a redução da realidade a formas geométricas amplia ainda mais as percepções e leituras sobre o mundo, pois escapa do reino da semelhança enquanto modalidade estritamente representativa, gerando realidades "autônomas", ainda que conectadas com as realidades inventivas da ciência e da religião. Uma mescla, uma ponte, um ímã, as aquarelas de Af Klint são, assim, combinações de formas e cores que tentam expressar - não reproduzir - e criar realidades em si. Cada aquarela da artista é um universo inteiro e real: em si, por si e para si.

Assim, acreditamos que Hilma af Klint apresenta as dimensões daquilo que, por definição, é abstrato, virtual e irrepresentável, sendo precisamente isso que dá sentido à proposição de Klee, mencionada por Deleuze, de que "a tarefa da pintura é definida como a tentativa de tornar visíveis forças que não o são [...] não reproduzir o visível, mas tornar visível" (DELEUZE, 2002, p. 35). Seus trabalhos aproximam-se a grandes ficções, que apresentam tanta potência imaginativa quanto o átomo, que, segundo Vaihinger (2011), antes de ser concreto, foi “pura imaginação". Desse modo, o movimento que Af Klint parece realizar em suas aquarelas é o da sobreposição de camadas de invenção (de viés estético, religioso e científico), de imaginação e ficção, sem a propriedade da permanência, de definições e certezas.

O espaço da ficção criado em suas obras ganha relação com a possibilidade de acesso a outras realidades, que se embaralham e duplicam, fazendo com que o invisível e impossível (o virtual) acabe por tornar-se possível na materialização estética, esta uma ponte para a potencialização de outros mundos imaginários. Pensar o espaço artístico projetado por Af Klint

\footnotetext{
14 "Não sendo extraído ou abstraído, mas criado de uma só vez, é algo concreto" - tradução do revisor.

15 "são universos completos e reais que existem em-por-e para si mesmos na mesma medida em que o Universo real não artístico" - tradução do revisor.
} 


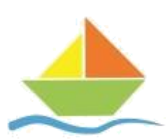

e seus desdobramentos com a ciência é dissolver lentamente algumas de nossas percepções já calcificadas e projetar novas visões sobre as infinitas possibilidades de leitura da realidade.

Assim, conforme já abordamos, ao afirmar que o conhecimento científico está alicerçado sobre uma base ficcional, Vaihinger (2011) evidencia o fato de que toda a estrutura do conhecimento está atrelada à ficção e que esta atua o tempo todo sobre nós, pois, antes de tudo, a ficção é, segundo o teórico, o grande instrumento de compreensão do mundo. Entrelaçando tal pensamento às obras da artista, conseguimos visualizar as necessidades dessa em buscar na imaginação um lugar para sustentar-se, construindo, a partir do viés estético, obras que jorram uma potência nômade de trânsito entre as distintas dimensões do pensamento, visto que ela desliza entre dois mundos imaginativos com uma destreza fascinante, sendo sensível e captando os pontos de contato entre eles, gerando infinitas possibilidades de leitura do mundo.

Seu trabalho funda (assim como a ciência) sua própria realidade, constrói mundos próprios e imaginários, realidades outras, não servindo como ferramenta para representar ou significar, não pretendendo dizer isto ou aquilo, apenas sendo e projetando (novos) mundos que resultam do amálgama e da fusão de realidades diversas.

\section{CONSIDERAÇÕES FINAIS}

O que não conseguimos compreender é concretizado pela imaginação; e aquilo que conseguimos inúmeras vezes também ganha uma dimensão imaginativa. Bordeando - e não formalizando - os sentidos dos mundos imaginativos de Hilma af Klint é que este exercício da escrita, em certa medida tão ficcional e inventivo quanto a sua obra, pensou o pensamento. $\mathrm{O}$ trabalho de Af Klint - mundo subvertido que se afasta do que interessa à vida prática - tende para o entrelugar, para o limite, para a terceira margem.

Em The Atom Series há comportas de significação (e da imaginação ficcional) que se abrem para que os significados escorram livres, soltos e sem sinal de amarras, uma vez que são retroalimentados por modos de pensar o conhecimento que são desiguais, mas cuja base (vaihingeriana) apresenta a ficção como alicerce de sustentação.

Assim, foi nesse encontro que vimos delinear-se, a partir de seus "mundos possíveis", bordas do saber que não se cristalizam, que não obedecem fronteiras. Ao contrário, chamam para um olhar que espreita na fenda, que ressoa, reflete, desvia e aponta para outros percursos, para novos caminhos e fluxos de naturezas diversas. Estudar seus "mundos" é encontrar 
caminhos que nos levam às margens, onde ainda é possível existir e aproximar fronteiras, materializando a possibilidade alegre e viva do encontro, do ser-ímã.

\section{REFERÊNCIAS BIBLIOGRÁFICAS}

BATAILLE, Georges. A parte maldita: precedida de "A noção de dispêndio". Belo Horizonte: Autêntica, 2013.

CHELES CRUZ, Anna Carolina. Hilma af Klint: do espírito à matéria. In: Palíndromo, v. 11, n. 24, p. 42-58, maio 2019.

http://www.revistas.udesc.br/index.php/palindromo/article/view/13326>

DELEUZE, G. Francis Bacon: logique de la sensation. Paris: Éditions du Seuil, 2002.

DELEUZE E GUATTARI. Mil platôs: capitalismo e esquizofrenia. v. 2. Coordenação da tradução Ana Lúcia de Oliveira. São Paulo: Editora 34, 1980.

. O que é filosofia? São Paulo: Editora 34, 1991.

DE ZEGHER, Catharine. "Abstract," in $3 \times$ Abstraction: New Methods of Drawing; Hilma af Klint, Emma Kunz, and Agnes Martin. New York: Yale University, 2005.

DIDI-HUBERMAN, Georges. O Que Vemos, O Que Nos Olha. 1a. ed. São Paulo: Editora, 1998.

FLUSSER, Vilém. Natural:Mente: vários acessos ao significado de natureza. São Paulo: Annablume, 2011.

ISER, Wolfgang. O ato da leitura. v. I. São Paulo: Editora 34, 1996.

KOJÉVE, A. Las pinturas concretas de Kandinsky. Madri: Editora Abada. 2007.

RYLE, Jadranka. Feminine Androgyny and Diagrammatic Abstraction: Science, Myth and Gender in Hilma af Klint's Paintings, 2019.

< https://birchandstar.files.wordpress.com/2019/05/the-idea-of-north-jadranka-ryle.pdf $>$

ROLIM. José Henrique Fabre. Hilma af Klint, complexidade filosófica da existência, 2018 https://arteref.com/opiniao/hilma-af-klint-complexidade-filosofica-da-existencia

ROSENBERG, Raphael. Was There a First Abstract Painter? Af Klint's Amimetic Images and Kandinsky's Abstract Art in Hilma af Klint: The Art of Seeing the Invisible. Stockholm: Axel and Margaret Axson Johnson Foundation, 2015.

https://www.academia.edu/14205210/About the essay_volume_Hilma_af_Klint_The_Art_of Seeing the Invisible>

VAIHINGER, Hans. A filosofia do como se. Chapecó: Argos, 2011.

Figura $\mathrm{n}^{\mathrm{o}} 3$ e $\mathrm{n}^{\mathrm{o}}$ 4: The Atom Series, $1917<$ https://www.guggenheim.org/artscurriculum/topic/science> 